\title{
HUBUNGAN PEMAKAIAN POPOK SEKALI PAKAI PADA BALITA (USIA 0-3 TAHUN) DENGAN TERJADINYA DERMATITIS ALERGI POPOK DI PURWOHARJO BANYUWANGI
}

\author{
Ayuk Naimah \\ (Universitas Bakti Indonesia, Fakultas Ilmu Kesehatan, Program studi d3 \\ Kebidanan, ayuknaimah@gmail.com)
}

\begin{abstract}
ABSTRAK
Badan Kesehatan Dunia (WHO) pada tahun 2009 prevalensi iritasi kulit (ruam popok) pada bayi cukup tinggi $25 \%$ dari 6.840 .507 .000 bayi yang lahir di dunia kebanyakan menderita iritasi kulit (ruam popok) akibat penggunaan popok. Angka terbanyak ditemukan pada usia 6-12 bulan. Tujuan penelitian ini adalah untuk mengetahui Hubungan Pemakaian Popok Sekali Pakai Pada Balita (Usia 0-3 Tahun) dengan Terjadinya Dermatitis Alergi Popok di wilayah kerja Puskesmas Purwoharjo Banyuwangi. Penelitian ini menggunakan metode Analitik Korelasi di mana rancangan penelitian yang di gunakan adalah Cross Sectional, populasinya adalah ibu yang mempunyai Balita (Usia 0-3 Tahun) di wilayah kerja Puskesmas Purwoharjo Banyuwangi sebanyak 29 responden. Teknik sampling yang digunakan Total Sampling. pengumpulan data dengan observasi dan kuesioner serta di analisis menggunakan uji Korelasi Spearman Rank dengan proses SPSS denganversi17. Hasil penelitian menyatakan sebagian besar responden mempunyai frekuensi pemakaian popok sekali pakai dalam kategori lama sebanyak 16 responden $(55,2 \%)$, dan sebagian besar dari responden mempunyai anak yang mengalami Dermatitis popok dengan kategori berat sebanyak 20 responden $(69,0 \%)$. Hasil uji statistik di dapatkan Spearman hitung dalam penelitian ini yaitu $(0,819)>(0,491)$ nilai spearman tabel, yang artinya Ho ditolak dan Ha diterima atau Ada Hubungan Pemakaian Popok Sekali Pakai Pada Balita (Usia 0-3 Tahun) dengan Terjadinya Dermatitis Alergi Popok wilayah kerja Puskesmas Purwoharjo Banyuwangi. Dari hasil penelitian, dapat di simpulkan bahwa penggunaan popok yang lama akan berdampak terjadinya dermatitis. Maka sebaiknya di sarankan bagi responden untuk mengganti popok sekali pakai pada anak dalam durasi waktu yang sebentar untuk menanggulangi terjadinya dermatitis.
\end{abstract}

Kata Kunci : Pemakaian Popok Sekali Pakai, Dermatitis AlergiPopok.

\begin{abstract}
The World Health Organization (WHO) in 2009 the prevalence of skin irritation (diaper rash) in infants is high enough 6.840507 billion 25\% of babies born in the world mostly suffering from skin irritation (diaper rash) due to the use of diapers. Figures were observed at the age of 6-12 months. The purpose of this study was to determine the relationship Use Diaper Disposal In Toddlers (Ages 0-3 Years) with the occurrence of Allergy Dermatitis Diaper in working area puskesmas Purwoharjo Banyuwangi. Analytical method used in this study correlations where the research design used is cross sectional, population is mothers with toddlers
\end{abstract}


(age 0-3 years) in the working area puskesmas Purwoharjo Banyuwangi many as 29 respondents. The sampling technique total sampling. Data collection techniques by observation and questionnaires and analyzed using Spearman Rank Correlation test with SPSS process with version 17. The study states that most of the respondents have a frequency of usage of disposable diapers in the old category as many as 16 respondents (55.2\%), and most of the respondents have children who have diaper dermatitis with weight categories of 20 respondents (69.0\%). Spearman statistical test results obtained in this research that count (0.819)> (0.491) Spearman value table, which means that Ho is rejected and Ha received or Ada Relations Disposable Diaper Use In Toddlers (Ages 0-3 Years) with the occurrence of Allergy Dermatitis Diaper in working area puskesmas Purwoharjo Banyuwangi. From the results, it can be concluded from the results of the study suggest that the use of disposable diapers with a long duration of replacement that will have an impact on children, namely dermatitis. Then it should be recommended for the respondent to replace the disposable diaper on the child within a short duration of time and or replace whenever toddler waste water to combat dermatitis.

Keywords: Use of Disposable Diapers, Diapers Allergy Dermatitis.

\section{PENDAHULUAN}

\section{Latar Belakang}

Popok dan bayi adalah dua hal yang tak bisa dilepaskan. Namun bagai pedang bermata dua, popok bisa membuat bayi tenang tapi bisa juga justru jadi sumber kerewelan mereka. Dan semua itu bergantung pada seberapa jeli kita mendeteksi kehadiran ruam popok. Diantara sejumlah gangguan kulit pada bayi, ruam popok adalah yang paling sering terjadi pada bayi baru lahir. Waspada bila kulit disekitar bokong bayi meradang, berwarna kemerahan. Itu tandanya bayi terkena ruam popok. Biasanya, ruam kulit ini membuat si kecil merasa gatal. Kenapa disebut ruam popok (diaper rash)? Karena, gangguan kulit ini timbul di daerah yang tertutup popok, yaitu sekitar alat kelamin, bokong, serta pangkal paha bagian dalam, (Hidayat R, 2011)

Kulit merupakan salah satu aspek vitalyang perlu diperhatikan dalam higiene setiaporang. Kulit sebagai pembungkus yang elastik, yang melindungi tubuh dari pengaruh lingkungan, dan bersambungan dengan selaput lendir yangmelapisi rongga- rongga dan lubang- lubang masuk kulit. Begitu vitalnya kulit, maka setiap adagangguan dalam kulit dapat menimbulkan berbagai masalah yang serius dalam kesehatan. Sebagai organ yang berfungsi sebagai proteksi, kulit memagang peranan penting dalam meminimalkan setiap gangguan dan ancaman yang akan masuk melewati kulit, (Laily, I. 2012)

Dermatitis popok merupakan salah satu masalah kulit pada bayi dan anak, Berdasarkan data yang dikeluarkan oleh Badan Kesehatan Dunia (WHO) pada tahun 2009 prevalensi iritasi kulit (ruam popok) pada bayi cukup tinggi $25 \%$ dari 6.840.507.000 bayi yang lahir di dunia kebanyakan menderita iritasi kulit (ruam popok) akibat penggunaan popok. Angka terbanyak 
ditemukan pada usia 6-12 bulan. (Hidayat, R. 2011)

Elleair International

Manufacturing Indonesia (EIMI) yang merupakan perusahaan pabrik popok terbesar di indonesia mengatakan, jumlah pengguna popok Sekali Pakai di Indonesia hanya 35\% dari populasi bayi yang saat ini mencapai 4 juta jiwa. (Shozo, I. 2016)

Sedangkan

prevalensi

Dermatitis pada bayi menurut Badan Pusat Statistik Jawa timur, di daerah Banyuwangi angka kejadian Dermatitis Diapers (Ruam Popok) berkisar antara $7-35 \%$ dari jumlah populasi balita dengan angka terbanyak pada usia 9-12 bulan. (BPS Jatim, 2009)

Berdasarkan studi pendahuluan yang dilakukan peneliti wilayah kerja puskesmas Purwoharjo Banyuwangi pada tanggal 12 september 2017, jumlah bayi dan balita yang menggunakan popok sebanyak 43 balita dan terkena Dermatitis popok sebanyak 29 balita.

Dampak Menggunakan Popok Sekali Pakai yang sering terjadi adalah Kelembaban akibat tumpukan air seni atau tinja yang menjadi tempat paling menyenangkan bagi bakteri dan jamur untuk berkembang biak dan menyebar. Dengan kata lain, popok sekali pakai tadi menjadi tak higienis lagi. Dari sinilah, iritasi kulit terjadi, gejalaawal terlihat dari kulit yang kemerahan,bahkan bisa menjadi radang kulit (dermatitis). Yang lebih parah, jika bagian anus kena iritasi, akan cepat menyebar ke alat kelamin dan lipatan pangkal paha. Akibatnya, terjadi infeksi sekunder di kedua daerah tersebut, bayipun menjadi rewel karena ia merasa kulitnya gatal, perih, dan panas.Bahan diaper sendiri bisa menimbulkan alergi pada kulit bayi. Karena tiap bayi punya kepekaan kulit sendiri-sendiri.Yang pasti, kalau sudah timbul merah-merah di kulit, diikuti lecet atau melepuh seperti bisul air, berarti alerginya sudah akut.Kasus yang paling sering terjadiadalah warna kemerahan di sekitar daerah yang langsung berhubungan dengan diaper, yaitu anus, alat kelamin, serta lipatan pangkal paha.

Untuk menghindari serta mencegah timbulnya Dermatitis popok pada balita, hendaknya para orang tua mengerti faktor utama dari terjadinya dermatitis tersebut. Upaya penanggulangan dari dermatitis popok sebenarnya sangat mudah, seperti sering mengganti popok sehabis anak buang air, menjaga kelembaban kulit daerah popok pada anak, dan yang tidak lupa para orang tua harus pintar memilih bahan popok yang bagus dan baik untuk anak. Seperti, popok yang berbahan halus, popok dengan daya tampung dan daya serap tinggi.

Berdasarkan pernyataan latar belakang diatas peneliti tertarik untuk meneliti " Hubungan Pemakaian Popok Sekali Pakai pada Balita (Usia 0-3 Tahun) dengan Terjadinya Dermatitis Alergi Popok di wilayah kerja puskesmas Purwoharjo Banyuwangi Tahun 2017”.

\section{Rumusan Masalah}

Adakah hubungan pemakaian Popok Sekali Pakai pada Balita (Usia 0-3 Tahun) denganterjadinya Dermatitis Alergi Popok di wilayah kerja puskesmas Purwoharjo Banyuwangi Tahun 2017? 


\section{Tujuan Penelitian \\ Tujuan Umum}

Untuk mengetahui hubungan Pemakaian Popok Sekali Pakai pada Balita (Usia 0-3 Tahun) dengan Terjadinya Dermatitis Alergi Popok di wilayah kerja puskesmas Banyuwangi Tahun 2017.

\section{Tujuan Khusus}

a. Mengidentifikasi pemakaian popok sekali pakai pada Balita (Usia 0-3) Tahun di wilayah kerja puskesmas Purwoharjo Banyuwangi Tahun 2017.

b. Mengidentifikasi terjadinya dermatitis alergi popok pada balita (Usia0-3 Tahun) di wilayah kerja puskesmas Purwoharjo Banyuwangi Tahun 2017.

c. Menganalisa hubungan pemakaian popok sekali pakai pada balita (usia 0-3 tahun) dengan terjadinya dermatitis alergi popok di wilayah kerja puskesmas Purwoharjo Banyuwangi Tahun 2017.

\section{METODE PENELITIAN}

Jenis penelitian yang digunakan peneliti adalah survey analitik, dengan pendekatan cross sectional. Populasi dalam penelitian ini adalah Populasi semua ibu yang mempunyai anak usia 0-3 tahun yang mengalami Dermatitis yaitu sebanyak 29 orang. Dalam penelitian ini peneliti menggunakan sampling jenuh (total sampling). Instrument yang di gunakan dalam penelitian ini adalah menggunakan lembar kuasioner dan observasi. Uji statistik yang digunakan adalah uji korelasi rank sperman. untuk menganalisis hubungan berbentuk ordinal (Sugiyono, 2009). Dalam penarikan kesimpulan uji Korelasi Spearman Rank yaitu jika nilai Spearman rank hitung >nilai Spearman rank tabel maka Ho ditolak dan Ha diterima yang berarti ada hubungan/ pengaruh. Sedangkan jika Spearman rank hitung < nilai Spearman rank tabel maka Ho diterima dan $\mathrm{Ha}$ ditolak yang berarti tidak ada hubungan/pengaruh. Selain cara tersebut pengambilan keputusan hipotesis dalam uji korelasi spearman rank juga dapat diambil dari nilai sig 2tailed dengan cara, jika nilai sig. 2 tailed < nilai taraf signifikan $(0,01)$ maka Ha diterima dan jika nilai sig. 2 tailed $>$ nilai taraf signifikan $(0,01)$ maka Ho yang diterima.

\section{HASIL}

Tabel I: Distribusi Frekuensi Responden Berdasarkan Pemakaian Popok Sekali Pakai Di Wilayah kerja Puskesmas Purwoharjo Banyuwangi Tahun2017

\begin{tabular}{|l|l|l|c|}
\hline & Pemakaian & Frekuensi & Prosentase (\%) \\
\hline Kategori & Lama & 16 & $55.2 \%$ \\
\cline { 2 - 4 } & cukup lama & 8 & $27.6 \%$ \\
\cline { 2 - 4 } & Sebentar & 5 & $17.2 \%$ \\
\cline { 2 - 4 } & Total & 29 & $100.0 \%$ \\
\hline
\end{tabular}

Sumber : kuesioner penelitian 
Berdasarkan Tabel 1 diketahui bahwa prosentase Pemakaian Popok Sekali Pakai pada responden adalah sebagian besar responden mempunyai frekuensi pemakaian popok sekali pakai dalam kategori lama sebanyak 16 responden $(55,2 \%)$, dan sebagian kecil lainnya mempunyai kebiasaan pemakaian popok sekali pakai dengan kategori sebentar sebanyak 5 responden $(17,2 \%)$.

Tabel 2: Distribusi Frekuensi Responden Berdasarkan Terjadinya Dermatitis Di Di Wilayah Kerja Puskesmas Purwoharjo Banyuwangi Tahun2017

\begin{tabular}{|l|l|c|c|}
\hline & Dermatitis & Frekuensi & Prosentase (\%) \\
\hline Kategori & Berat & 20 & $69.0 \%$ \\
\cline { 2 - 4 } & Sedang & 1 & $3.4 \%$ \\
\cline { 2 - 4 } & Ringan & 8 & $27.6 \%$ \\
\cline { 2 - 4 } & Total & 29 & $100.0 \%$ \\
\hline
\end{tabular}

Sumber : kuesioner penelitian

Berdasarkan Tabel 2 diketahui bahwa prosentasekejadian Dermatitis pada anak responden adalah sebagian besar dari responden mempunyai anak yang mengalami Dermatitis popok dengan kategori berat sebanyak 20 responden $(69,0 \%)$ dan sebagian kecil mengalami dermatitis dengan kategori sedang sebanyak 1 responden $(3,4 \%)$.

Tabel 3

Tabulasi Silang Antara Pemakain Popok Sekali Pakai Dengan Terjadinya Dermatitis Popok Di Wilayah kerja Puskesmas Purwoharjo Banyuwangi Tahun2017

\begin{tabular}{|c|c|c|c|c|c|c|c|c|c|}
\hline & \multicolumn{6}{|c|}{ Terjadinya Dermatitis Popok } & \multirow{2}{*}{\multicolumn{2}{|c|}{ Total }} \\
\hline & & \multicolumn{2}{|c|}{ Berat } & \multicolumn{2}{|r|}{$\begin{array}{c}\text { Sedan } \\
\mathrm{g}\end{array}$} & \multicolumn{2}{|c|}{$\begin{array}{l}\text { Ringa } \\
\mathrm{n}\end{array}$} & & \\
\hline & & $\mathrm{N}$ & $\%$ & $\mathrm{~N}$ & $\%$ & $\mathrm{~N}$ & $\%$ & $\mathrm{~N}$ & $\%$ \\
\hline \multirow{3}{*}{$\begin{array}{c}\text { Pemak } \\
\text { aian } \\
\text { Popok } \\
\text { Sekali } \\
\text { Pakai }\end{array}$} & Lama & 16 & $\begin{array}{r}55,2 \\
\%\end{array}$ & 0 & 0 & 0 & 0 & 16 & $\begin{array}{r}55,2 \\
\%\end{array}$ \\
\hline & $\begin{array}{l}\text { Cukup } \\
\text { Lama }\end{array}$ & 4 & $\begin{array}{r}13,8 \\
\%\end{array}$ & 1 & $3,4 \%$ & 3 & $\begin{array}{l}10,3 \\
\%\end{array}$ & 8 & $\begin{array}{r}27,6 \\
\% \\
\end{array}$ \\
\hline & \begin{tabular}{|l} 
Sebenta \\
$\mathrm{r}$
\end{tabular} & 0 & 0 & 0 & 0 & 5 & $\begin{array}{l}17,2 \\
\%\end{array}$ & 5 & $\begin{array}{r}17,2 \\
\% \\
\end{array}$ \\
\hline & Total & $\begin{array}{l}2 \\
0\end{array}$ & $\begin{array}{r}69,0 \\
\%\end{array}$ & 1 & $3,4 \%$ & 8 & $\begin{array}{l}27,6 \\
\%\end{array}$ & 29 & $\begin{array}{r}100 \\
\%\end{array}$ \\
\hline
\end{tabular}

Sumber : Hasil Pengolahan Data Kuesioner (2017)

Dari hasil Tabel 3 diperoleh data Hubungan Pemakaian Popok Sekali Pakai Pada Balita (Usia 0-3 Tahun) dengan Terjadinya Dermatitis Alergi Popok didapat porsentase yaitu sebagian besar dari responden mempunyai kebiasaan pemakaian popok yang lama dan mengalami dermatitis berat sebanyak 16 responden $(55,2 \%)$ dan sebagian kecil responden mempunyai frekuensi pemakaian popok sekali pakai 
dengan kategori cukup lama dan mempunyai anak yang mengalami dermatitis sedang sebanyak 1 responden $(3,4 \%)$.

Dari hasil uji statistik penelitian dapat disimpulkan bahwa dalam penelitian ini menggunakan uji Korelasi Spearman Rank dengan taraf signifikan 0,01 dengan nilai Spearman's tabel sebesar 0,491. Dari tabel diatas dapat diketahui nilai spearman rank hitung sebesar 0,819 .

Dalam penarikan kesimpulan uji Korelasi Spearman Rank yaitu jika nilai Spearman rank hitung $>$ nilai Spearman rank tabel maka Ho ditolak dan Ha diterima yang berarti ada hubungan/ pengaruh. Sedangkan jika Spearman rank hitung < nilai Spearman rank tabel maka Ho diterima dan Ha ditolak yang berarti tidak ada hubungan/pengaruh.

Selain cara tersebut pengambilan keputusan hipotesis dalam uji korelasi spearman rank juga dapat diambil dari nilai sig 2tailed dengan cara, jika nilai sig. 2 tailed < nilai taraf signifikan $(0,01)$ maka Ha diterima dan jika nilai sig. 2 tailed $>$ nilai taraf signifikan $(0,01)$ maka Ho yang diterima.

Jadi melihat nilai Spearman hitung $(0,819)>(0,491)$ nilai spearman tabel, yang artinya Ho ditolak dan $\mathrm{Ha}$ diterima atau Ada Hubungan Pemakaian Popok Sekali Pakai Pada Balita (Usia 0-3 Tahun) dengan Terjadinya Dermatitis Alergi Popok Di Wilayah kerja Puskesmas Purwoharjo Banyuwangi Tahun 2017.

Selain itu, diketahui juga nilai sig. 2tailed $(0,000)<(0,01)$ taraf signifikan, yang berarti Ha diterima atau Ada Hubungan Pemakaian Popok Sekali Pakai Pada Balita (Usia 0-3 Tahun) dengan Terjadinya Dermatitis Alergi Popok di Di
Wilayah kerja Puskesmas Purwoharjo Banyuwangi Tahun2017

\section{PEMBAHASAN}

\section{Berdasarkan hasil penelitian diketahui bahwa prosentase} Pemakaian Popok Sekali Pakai pada responden adalah sebagian besar responden mempunyai frekuensi pemakaian popok sekali pakai dalam kategori lama sebanyak 16 orang $(55,2 \%)$, dan hampir setengah responden yaitu sebanyak 8 orang $(27,6 \%)$ mempunyai kebiasaan pemakaian popok sekali pakai dengan kategori cukup lama serta sebagian kecil lainnya mempunyai kebiasaan pemakaian popok sekali pakai dengan kategori sebentar sebanyak 5 orang $(17,2 \%)$.

Selain itu, didapat frekuensi Pendidikan responden yaitu sebagian besar dari responden mempunyai tingkat pendidikan SMA sebanyak 16 responden $(55,2 \%)$ dan sebagian kecil dari responden berpendidikan SD sebanyak 3 responden (10,3\%), faktor yang mempengaruhi pemakai popok dengan frekuensi lama pada responden yaitu kurangnya pengetahuan responden akan tata cara penggunaan popok yang benar, sebab mayoritas responden hanya lulusan SMA bahkan ada yang lulusan SMP dan SD serta tidak adanya responden yang berpendidikan Akademik sehingga responden kurang mengerti tentang kesehatan anak.

Dalam penelitian terdahulu juga didapatkan hasil penelitian bahwa sebagian besar responden tergolong kategori sangat jarang dalam menggantikan pemakaian disposible diaper dengan jumlah 17 responden $(53 \%)$. Ini dikarenakan sebagian besar responden 
mempunyai pekerjaan sebagai ibu rumah tangga sebanyak 21 orang $(66 \%)$. Dengan berprofesi sebagai ibu rumah tangga yang tidak memiliki penghasilan selain penghasilan dari suami, secara tidak langsung kemampuan untuk membeli disposible diaper (Popok sekali pakai) juga rendah.Kalaupun mampu untuk membelinya, itupun digunakan dalam jangka waktu yang lama untuk menghemat biaya atau menekan pengeluaran.

Disposible diaper sering disebut popok sekali pakai.popok sendiri di artikan sebagai alas bayi, disposible sendiri di artikan sebagai sesuatu yang dapat dibuang sesudah di pakai (diaper dengan bermacammacam merek yang tersedia di supermarket) dengan menggunakan bahan ekstra penyerap sehingga tidak mengenai kulit bayi. Disposible diaper ini terdiri dari lembaran dan tahan air dan lapisannya mengandung bahan penyerap. Penting sekali memperhatikan daya tampung disposible diaper karena hal ini dapat kita jadikan acuan kapan kira-kira disposible diaper perlu diganti. Disposible diaper yang beredar dipasaran beragam jenisnya. Ada yang tahan sampai 10 kali kencing. Tapi ada juga yang hanya tahan 4-5 kali kencing, jika disposible diaper sudah penuh dan harus diganti 1 jam yang lalu.karena sudah tidak bisa menampung urin bayi. Hal ini menimbulkan iritasi pada kulit bayi. Menurut Muhandari, 2009). Pada prinsipnya jangan sampai air kencing melebihi daya tampung disposible diaper. Juga, perhatikan volume kencing si kecil.Ada bayi yang volume kencingnya sedikit sehingga pemakaian disposible diaper bisa lebih lama, tetapi ada juga bayi yang volume kencingnya sangat banyak. Maksudnya bila aturan yang tertera hingga 10 kali kencing mungkin pada bayi yang volume kencingnya banyak bisa kita perkirakan hingga 8 kali kencing saja.

Dari ulasan hasil penelitian saat ini dan penelitian sebelumnya serta ditunjang dengan teori, maka peneliti dapat menyimpulkan bahwa popok sekali pakai yaitu diartikan sebagai alas bayi yang dapat dibuang sesudah dipakai, namun pemakaian tersebut mempunyai aturan jangka penggantian salah satunya setiap kali bayi membuang air, namun dengan melihat hasil penelitian baik penelitian saat ini ataupun yang terdahulu masih banyak masyarakat yang memakaikan popok sekali pakai pada anak dengan kategori jangka lama sehingga terjadi banyak keluhan pada bayi seperti adanya bintik kemerahan.

Berdasarkan Tabel 2 diketahui bahwa prosentase kejadian Dermatitis pada anak responden adalah sebagian besar dari responden mempunyai anak yang mengalami Dermatitis popok dengan kategori berat sebanyak 21 responden $(69,0 \%)$, sebagian kecil mengalami dermatitis dengan kategori sedang sebanyak 1 orang $(3,4 \%)$ serta hampir setengah dari responden sebanyak 8 orang $(27,6 \%)$ mengalami dermatitis dengan kategori ringan.

Data umum didapat prosentase Jumlah Anak responden yaitu hamir setengahnya lagi mempunyai 2-3 anak sebanyak 14 orang $(48,3 \%)$ dan sebagian kecil lainnya sebanyak 2 responden $(6,9 \%)$ mempunyai >3anak. Faktor terjadinya dermatitis pada anak responden salah satunya disebabkan oleh jumlah anak responden yang 
mayoritas mempunyai anak lebih dari 2 sehingga pengurusan responden terhadap anak terbagi dan tidak fokus.

Hal tersebut sama seperti penelitian terdahulu yang dilakukan oleh Irmania Januarti (2014) yang menyatakan dalam penelitiannya bahwa setengah responden yang mengalami Diaper Rash (ruam popok ) berat yaitu 15 responden atau $(46 \%)$ responden termasuk dalam kategori diaper rash (ruam popok ) sedang, sedangkan 11 responden termasuk kategori diaper rash (ruam popok) ringan.

Diaper rash (Ruam Popok) dapat di anggap sebagai salah satu jenis diaper rash kontak iritan. Sebagai reaksi terhadap kelembaban yang berlebihan pada kulit, gesekan, maserasi dan kontak lama dengan urin dan tinja, sabun popok yang tertahan dan sediaan topikal, kulit pada daerah popok dapat menjadi eritema dan berskuama, seringkali dengan lesi populovesikel dan bula, fisura dan erosi (Nelson, 2003).

Berdasarkan hasil penelitian di atas didapatkan sebagian besar bayi mengalami Diaper Rash (Ruam Popok) dengan kategori berat sebanyak 15 responden. Diaper rash dapat disebabkan oleh kebersihan kulit yang kurang. Mencuci popok yang kurang bersih dapat memicu terjadi Diaper rash (Ruam Popok). Kurangnya pengetahuan dapat memicu terjadinyaDiaper Rash (Ruam Popok) tergolong kategori berat sejumlah 12 responden. Dengan pendidikan yang rendah sehingga memungkinkan memiliki pengetahuan yang kurang akan kesehatan bayinya.

Fakta lain menyebutkan bahwa 11 responden mengalami Diaper Rash (Ruam Popok) dengan kategori ringan. Ini dikarenakan pengetahuan yang baik dari orang tuanya. Sebanyak 7 responden berpendidikan hingga perguruan tinggi. Dengan tingginya tingkat pengetahuan, seseorang dapat menjaga kesehatan dengan berperilaku hidup sehat. Diaper Rash (Ruam Popok) dapat disebabkan oleh bakteri. Bakteri ini tumbuh di kulit yang lembab dan hangat dengan pengetahuan yang dimiliki orang tua, setidaknya dapat mencegah terjadinya Diaper Rash (Ruam Popok) pada bayinya dengan cara menjaga kulit bayi agar tetap kering.

Pengetahuan orang tua yang cukup memadai terutama tentang dampak dari penggunaan popok tersebut, orang tua agar lebih siap dan sigap dalam merawat dan menjaga dari iritasi yang di timbulkan dengan penggunaan disposible diaper. Pengetahuan orang tua tersebut dapat diperoleh dari berbagai sumber informasi dari berbagai media baik elektronik maupun media massa dan juga peran aktif dari petugas kesehatan dalam hal ini penyuluhan- penyuluhan kesehatan yang diberikan.

Dilihat dari nilai Spearman hitung dalam penelitian ini yaitu $(0,819)>(0,491)$ nilai spearman tabel, yang artinya Ho ditolak dan $\mathrm{Ha}$ diterima atau Ada Hubungan Pemakaian Popok Sekali Pakai Pada Balita (Usia 0-3 Tahun) dengan Terjadinya Dermatitis Alergi Popok di wilayah kerja puskesmas Purwoharjo Banyuwangi.

Popok sekali pakai (Disposible Diaper) penggunaanya memang lebih praktis dibandingkan dengan popok pakai ulang karena penggunaannya dapat di buang sesudah pakai. Hal Ini dikarenakan disposible diaper terdiri dari lapisan 
yang tahan air dan lapisannya mengandung bahan penyerap dan gel poliakrilase sehingga tidak sampai terjadi kulit yang lembab. Kontak atau pemakaian lama antara kulit dan kelembaban menyebabkan pembengkakan dan mengganggu fungsi penahan kulit. Kulit cenderung lebih rentan terhadap gesekan dan lebih mudah mengalami iritasi dan mudah ditumbuhi jamur dan bakteri yang nantinya dapat menyebabkan Diaper rash (Ruam Popok).

Berdasarkan hasil penelitian diketahui bahwa prosentase Pemakaian Popok Sekali Pakai pada responden adalah sebagian besar responden mempunyai frekuensi pemakaian popok sekali pakai dalam kategori lama sebanyak 16 orang $(55,2 \%)$. Ini dikarenakan disposible diaper terdiri dari lembaran yang tahan air dan lapisannya mengandung bahan penyerap dan gel poliakrilase sehingga tidak sampai terjadi kulit yang lembab.Kontak/ pemakaian lama antara kulit dan kelembapan menyebabkan pembengkakan dan mengganggu fungsi penahan kulit. Kulit cenderung lebih rentan terhadap gesekan dan lebih mudah mengalami iritasi dan mudah ditumbuhi jamur dan bakteri yang nantinya dapat menyebabkan diaper rash (ruam popok).

Fakta lain menyebutkan bahwa sebagian besar dari responden mempunyai anak yang mengalami Dermatitis popok dengan kategori berat sebanyak (69,0\%). Faktor sosial ekonomi dan pendidikan dari orang tua responden sangat berpengaruh terhadap kesehatan bayinya agar anaknya terhindar dari iritasi kulit. Sehingga orang tua akan selalu memperhatikan lama penggunaan disposible diaper (popok sekali pakai), karena dengan pemakaian terlalu lama akan berakibat iritasi pada kulit bayinya.

\section{SIMPULAN}

1. Sebagian besar responden mempunyai frekuensi pemakaian popok sekali pakai dalam kategori lama sebanyak 16 responden $(55,2 \%)$.

2. Sebagian besar dari responden mempunyai anak yang mengalami Dermatitis popok dengan kategori berat sebanyak 20 responden $(69,0 \%)$.

3. Ada hubungan pemakaian popok sekali pakai pada balita (usia 03 tahun) dengan terjadinya dermatitis alergi popok di Wilayah Kerja Puskesmas Purwoharjo Banyuwangi

\section{DAFTAR PUSTAKA}

Anonim (2008). "Hubungan Lama penggantian Popok Sekali Pakai dengan terjadinya Dermatitis pada anak di R.A Darussalam Desa Sumber Mulyo, Jogoroto, Jombang" jurnal Kesehatan Anak; DIII Kebidanan FIK UNIPDU Jombang.

Azis, A, H (2007). Riset Keperawatan dan Teknik Penulisan Ilmiah, Edisi Pertama.Jakarta : Salemba Medik

Azwar, (2006). Reliabilitas dan validitas. Yogyakarta Pustaka Pelajar

Badan Pusat Statistik Jawa timur, (2009) di daerah Banyuwangi

Depkes, RI. 2011. Angka Kejadian Dermatitis. 
http://Tomkian.com diakses tanggal 20 April 2012

Diena.(2009). Neonatus dan Asuhan Keperawatan Anak.Jakarta : EGC

Dinkes Jatim (2013) Profil

Kesehatan Provensi Jawa

Timur tahun 2012

Handy.(2011). Neonatus dan Asuhan

Keperawatan Anak. Nuha

Medika. Yogyakarta : 12-14

Hidayat. (2011). Metode penelitian

Keperawatan dan Teknik

Analisis Data. Jakarta:

Salemba Medika.

Irmania (2014). Pemakaian

Disposable Diapers Dengan

Terjadinya Diaper Rash

Pada Bayi Di Posyandu

Desa Gayaman Kecamatan

Mojoanyar Kabupaten

Mojokerto Irmania Januarti

Laily, I. (2012). Jurnal Ilmu

Pendidikan; "Pengaruh

Pemakaian Popok Terhadap

Terjadinya Dermatitis Pada

Anak Usia Toodler di

Kelompok B3 DEPAG 1 Palu

Barat", Universitas

Tadulako : A41108005.

Maryunani, A. (2010). Panduan

Penanganan Penyakit Kulit:

PT. Rineka Cipta.

Mayer, Gloria. (2008). Faktor-

Faktor pengaruh terjadinya

Dermatitis pada

Anak.Bandung : Mandar

Maju.

Mulyono, (2011). Pencegahan dan

Penanganan Dermatitis

.Bandung : PT. Remaja

Rosdakarya.

Neilson, J. (2009). Dermatitis Kulit pada Anak, Jakarta : Rineka Cipta.

Nursalam. (2013) Metodologi Penelitian Ilmu Keperawatan.
Jakarta:Salemba Medika. Edisi 3.

Nursalam. (2012). Konsep dan Penerapan Metodologi Ilmu Keperawatan. Padoman Skripsi, Tesis, dan Instrumen Penelitian Keperawaran. Surabaya : Salemba Medika.

Nursalam. (2008). Konsep dan Penerapan Metodologi Ilmu Keperawatan. Padoman Skripsi, Tesis, dan Instrumen Penelitian Keperawaran. Surabaya : Salemba Medika.

Nuryani. (2008), Panduan Lengkap Perawatan Untuk Bayi dan Balita,

Jakarta : Arcan.

Notoatmodjo, S. 2010. Ilmu Perilaku

Kesehatan.http://nikomang-

sugiartini.blogspot.com/20111

12/konsep-perilaku-dan-

perilaku-kesehatan.html. diakses 25 November 2011.

Rukiyah.(2010). Pencegahan dan pengobatan Dermatitis pada Anak. Bandung: Mandar Maju.

Sudarti. 2010. Kelainan dan Penyakit pada Bayi dan Anak. Nuha Medika. Yogyakarta : 15-20

Sugiyono (2009).Metode Penelitian Keperawatan dan Teknik Penulisan Ilmiyah.Jakarta : Salemba Medika

Suparyanto, (2012).

Penanggulangan Alergi Pada Anak. Edisi 1.Jakarta :

Salemba Medika. 